\title{
Squamous carcinoma of the penis and previous recurrent balanitis: a case report
}

\author{
J J R Fernando, T M Wanas
}

\begin{abstract}
A 33 year old uncircumcised Caucasian male who had a 7 year history of intermittent erosive balanitis and herpes, presented with an 18 month history of progressively worsening penile ulceration not responding to the usual medication. Biopsy of the glans penis carried out in view of the long standing ulceration showed a sqamous cell carcinoma of the penis. As there was no response to radiotherapy, partial penectomy was carried out. The importance of early biopsy is emphasised when ulcerative lesions of the penis do not respond adequately to medical therapy. Different treatment modalities available are reviewed.
\end{abstract}

\section{Introduction}

Carcinoma of the penis is rare in the western world accounting for less than $1 \%$ of all male malignancies. It can present as an exophytic lesion or as flat and ulcerative lesion mimicking benign conditions. Here we report a case of carcinoma of the penis presenting as an ulcerative lesion.

\section{Case report}

A 33 year old uncircumcised Caucasian male had two episodes of clinically typical herpetic lesions (not confirmed by viral culture) on the glans penis in late 1983 and early 1984 . He continued to have recurrences at intermittent intervals but was successfully treated for presumed erosive balanitis and herpes at various times with antifungal creams, acyclovir, hydrocortisone cream and saline baths until 18 months before presentation. From that time he began to have very frequent recurrences not responding to medication and over the past 4-6 months his symptoms were continuous and associated with worsening penile ulceration.

He has been twice married and has three children by his second wife. Neither his present wife nor his

Department of Genitourinary Medicine, Royal Hospital, Cleveland Road, Wolverhampton, UK J J R Fernando

T M Wanas first wife had any history of genital herpes or genital warts. He had had no other sexual contact outside his two marriages during the past eleven years. He also gave no history of any other sexually transmitted infections in the past. He is a plumber and he smoked 15 cigarettes a day until 3 months before presentation and drank 20 pints of lager per week.

Examination revealed widespread superficial ulceration of the glans penis with a tender, granular area $2.5 \mathrm{~cm} \times 2.5 \mathrm{~cm}$ on the dorsal aspect of the glans penis to the left of the urethral meatus. Examination of the urethra, scrotum and testes were normal. There was no evidence of inguinal lymphadenopathy.

He had full genital screening but the tests were negative for gonorrhoea, chlamydia, mycoplasma, ureaplasma and Trichomonas vaginalis. Subpreputial swab taken for candida was also negative. Serological tests for syphilis carried out over a three month period was also negative.

The only positive test was a swab taken for herpes simplex virus culture. In view of this he was commenced on a five day course of acyclovir $200 \mathrm{mg}$ three times a day. However, when he was reviewed 2 weeks

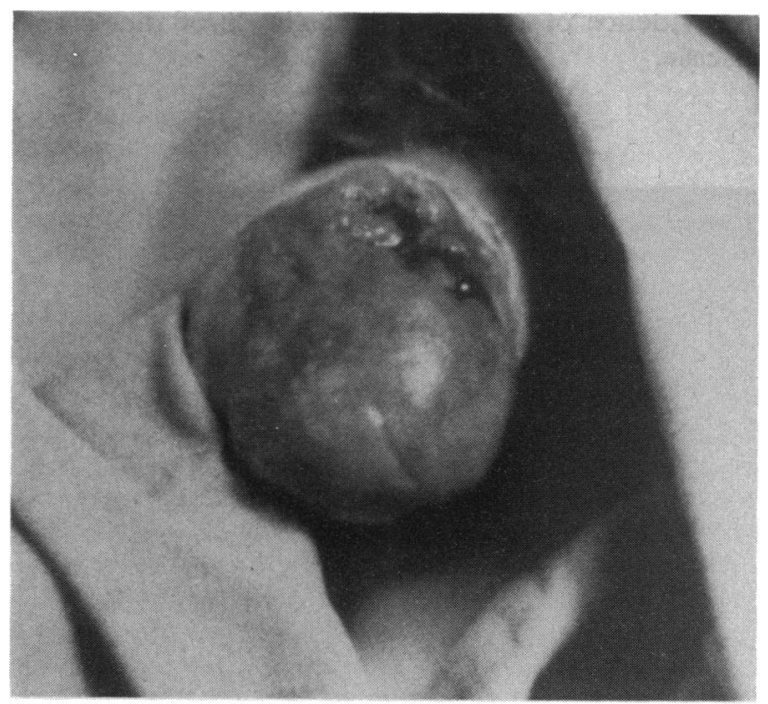

Figure 1 Widespread erosive balanitis with a $2.5 \mathrm{~cm} \times$ $2.5 \mathrm{~cm}$ ulcer on the dorsal aspect of glans. 


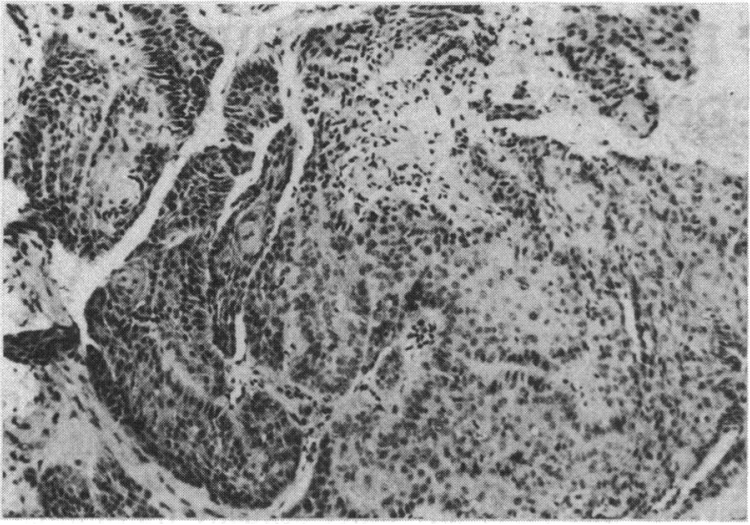

Figure 2 Well differentiated squamous cell carcinoma of the penis. (Haematoxylin and eosin. $\times 32$ ).

later, as there was no improvement in signs or symptoms and also in view of the long standing ulceration a penile biopsy was carried out under local anaesthetic and this revealed a well differentiated squamous cell carcinoma of the penis.

Various treatment options were discussed with the patient. In view of his age penile preservation was agreed upon. After circumcision under anaesthesia one week prior to radiotherapy, treatment was given by a direct field of $14 \mathrm{mV}$ electrons- $5000 \mathrm{cGy}$ in 15 daily fractions over a period of 25 days. Treatment was complicated by local infection which was satisfactorily treated with flucloxacillin and saline baths. At six weeks after radiotherapy, as a biopsy confirmed no tumour regression partial penectomy was carried out. Six months after surgery there was no evidence of recurrence locally or of metastatic disease.

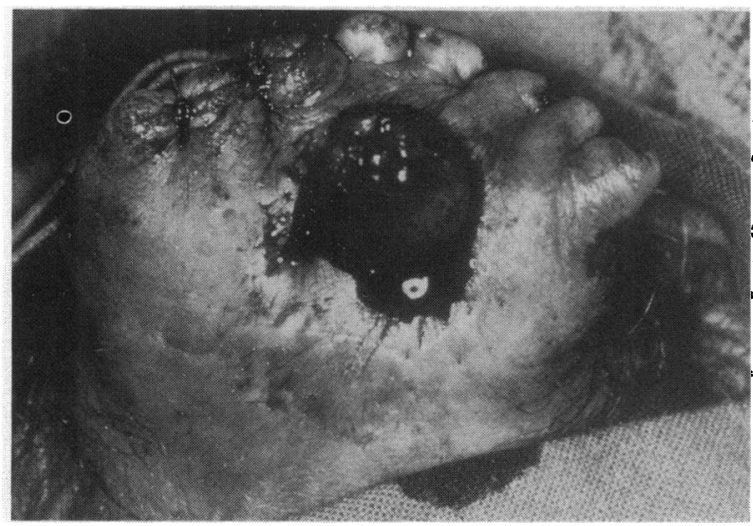

Figure 3 Post partial penectomy. Urethra brought out through button hole in ventral flap.

\section{Discussion}

Carcinoma of the penis accounts for $0.2 \%-0.4 \%$ of urogenital malignancies and less than $1 \%$ of all male malignancies in the United States and United Kingdom.

Carcinoma of the penis is almost unknown among those circumcised in the neonatal period. Its frequency, however, increases when circumcision is delayed until puberty. Adult circumcision offers little or no protection. It has been theorised that the neonatal glans exposed at circumcision may acquire a protective layer of cutaneous cornification that does not appear after delayed circumcision. ${ }^{1}$ Poor personal hygiene with resultant recurrent balanitis and phimosis is a recognised predisposing factor in carcinoma of the penis. ${ }^{23}$ The retention of smegma and carcinogenic agents within the preputial sac may account for its higher incidence in the uncircumcised.

Premalignant conditions include condyloma acuminata, Bushke-Lowenstein tumour, erythroplasia of Queyrat, Bowens disease, cutaneous horns, balanitis xerotica obliterans, Paget's disease and leukoplakia. These lesions may precede or coincide with carcinoma of the penis particularly in the uncircumcised.

Hellberg $^{3}$ et al have shown that the association between cigarette smoking and penile cancer was direct, related to the dose and independent of other known risk factors. They hypothesise that tobacco products could become concentrated in the smegma making it carcinogenic, especially in men with phimosis. Recently a viral aetiology has been proposed for carcinoma of the penis. HPV DNA 16 has been isolated in Bowenoid papulosis. ${ }^{4} \mathrm{HPV}$ DNA 16 and 18 have also been isolated in $49 \%$ of penile carcinoma specimens. ${ }^{5}$ Smoking and herpes simplex virus type 2 are thought to be necessary co-factors for progression and conversion of HPV induced lesion to a malignant state. ${ }^{6}$

Interestingly, a third of females who were the sole sexual partners of men with penile condylomata for 12 months or more were found to develop cervical intraepithelial neoplasia which too is thought to be associated with oncogenic viruses. ${ }^{7}$

Carcinoma of the penis can present as an exophytic lesion or, as in this case report, as a flat and ulcerative lesion. The latter has a tendency to earlier metastasis and is associated with a poor 5 year survival rate. ${ }^{8}$ The delay in presentation to medical care due to personal neglect, embarrassment, guilt, fear and ignorance may have a role in the poor prognosis. This may be compounded by further delay in diagnosis and initiation of appropriate treatment. ${ }^{1}$

Early biopsy is essential in the management of recurrent or persistent ulcerations of the penis. Since the mode and nature of therapy depends on the age of the patient, histological pattern and the extent of the 
spread, accurate localisation of the tumour is essential. Ultra-sonography ${ }^{9}$ can be useful in visualising both the extent of the primary tumour and spread to the inguinal lymph nodes. This enables the surgeon to decide on an appropriate level of penile amputation and the need for lymphadenectomy.

The aim of treatment is to preserve penile function and upright voiding especially in younger patients. Therefore, as in our patient radical radiotherapy is the treatment of choice. Limitations of radiotherapy include poor response, radionecrosis requiring amputation and urethral stenosis with or without stricture and fistula.

For superficial and flat lesions of the penis radiation therapy, microscopically controlled surgery ${ }^{10}$ radical carbon dioxide laser microsurgery ${ }^{11}$ or neodymium YAG laser ${ }^{12}$ have been advocated by different authors. Bleomycin with radiotherapy ${ }^{13}$ or microscopically controlled surgery ${ }^{10}$ has also been attempted for larger recurrent tumours. The success rate of these regimens cannot be evaluated because of the small numbers of patients and/or insufficient follow up.

When "conservative" treatment fails, partial or total penectomy is carried out.

\section{Management of metastasis}

Careful follow-up for a period of eighteen months to three years to detect any evidence of metastasis is essential if lymphadenectomy has not been performed as a primary procedure. Clinical examination is thought to provide a very poor assessment of lymphadenopathy especially so in obese individuals. The presence of secondary infection and lymphadenitis not uncommon with carcinoma of the penis also complicates the clinical diagnosis. The persistence of lymphadenopathy six weeks after surgery or radiotherapy may signify metastasis and ipsilateral inguinal lymphadenectomy is indicated. ${ }^{8}$

A better 5 year survival rate has been achieved when inguinal lymphadenectomy was performed as a primary procedure. ${ }^{14}$ This has also been associated with a lesser morbidity and mortality as opposed to when inguinal lymphadenectomy was performed as a secondary procedure especially in the presence of large ulcerated lymph nodes. ${ }^{14}$

An alternative approach may be to perform lymphangiography or biopsy of the sentinel node ${ }^{15}$ a lymph node at the junction of the saphenous vein and superior epigastric vein. If these nodes contain tumour, lymphadenectomy is performed. However, there have been instances when positive pelvic nodes have been found in spite of a negative sentinel node. ${ }^{16}$ Ultrasonography as previously mentioned may have a useful place in the future in determining the need for lymphadenectomy.

Penile carcinoma represents one of the few neoplasms for which a predictable and simple means of prophylaxis exists, namely circumcision carried out in the neonatal period. ${ }^{17}$ Carcinoma of the penis does not always present as an exophytic lesion. When penile ulcers do not respond to medical treatment early biopsy is essential to exclude a malignant process.

We thank Mr N Philp, Consultant Urologist, Dr D Fairlamb, Consultant Radiotherapist, Dr K Scott, Consultant Histopathologist, and the Department of Medical Illustration for the help and assistance given in preparing this paper.

Address for correspondence: $\operatorname{Dr} T M$ Wanas, Department of Genito-Urinary Medicine, Royal Hospital, Cleveland Road, Wolverhampton, WV2 1BT, UK.

1 Schellhammer PF, Grabstald H. Tumours of the Penis. In Harrison JH, Gittes RF, Perlmutter AD, Stamey TA, Walsh PC, eds. Campbell's Urology. 4th ed. Philadelphia: W B Saunders \& Co, 1979. Vol 2, Chap 33, 1171-89.

2 Narayana AS, Olney LE, Loening SA, Weimar GN, Culp DA. Carcinoma of the Penis-Analysis of 219 cases. Cancer 1982;49:2185-92.

3 Hellberg D, Valentin J, Eklund T, Nilsson S. Penile Cancer: is there an epidemiological role for smoking and sexual behaviour? BMJ 1987;295:1306-8.

4 Ikenberg H, Gissman L, Gross G, Grussendore-Conen EI, Zur Hausen $H$. Human papillomavirus type 16 related DNA in genital Bowen's Disease and in bowenoid papulosis. Int $J$ Cancer 1983;32:563-5.

5 McCance DJ, Kalache A, Ashdown K, et al. Human papillomavirus types 16 and 18 in carcinomas of the penis from Brazil. Int J Cancer 1986;37:55-9.

6 Zur Hausen $\mathrm{H}$. Herpes simplex virus in human genital cancer. Int Rev Exp Pathol 1983;25307-26.

7 Campion M, Singer A, Clarkson P, McCance DJ. Increased risk of cervical neoplasia in consorts of men with penile conylomata acuminata. Lancet 1985;i:943-6.

8 Schellhammer PF, Grabstald $H$. Tumours of the penis. In: Walsh PC, Gittes RF, Perlmutter AD, Stamey TA, eds. Campbell's Urology, 5th ed. Philadelphia: W B Saunders \& Co, 1986, Vol 2, Chap 34, 1583-606.

9 Yamashita T, Ogawa A. Ultrasound in penile cancer. Urol Radiol 1989;11:174-7.

10 Mohs FE, Snow SN, Messing EM, Kuglitsch ME. Microscopically controlled surgery in the treatment of carcinoma of the penis. J Urol 1985;133:961-6.

11 Bandieramonte G, Santoro O, Boracchi P, Piva L, Pizzocaro G, $\mathrm{De} P$ alo $\mathrm{G}$. Total resection of glans penis surface by $\mathrm{CO}_{2}$ laser microsurgery. Acta Oncologica 1988;27:575-8.

12 Von S Lenk, Heike Audring, Althaus P. Laser treatment of superficial penile tumours. Dermatologische Monatsschrift 1988;174:593-9.

13 Maiche AG. Combined bleomycin and radiation treatment of penile carcinoma. Acta Oncologica 1989;28:548-9.

14 Fraley EE, Zhang G, Manivel C, Niehans GA. The Role of ilioinguinal lymphadenectomy and significance of histological differentiation in treatment of carcinoma of the penis. $J$ Urol 1989;142:1478-82.

15 Cabanas RM. An approach for the treatment of penile carcinoma. Cancer 1977;39:456-66.

16 Perinetti E, Crane DB, Catalona NJ. Unreliability of sentinel lymph node biopsy for staging penile carcinoma. J Urol 1980;124:734-5.

17 Dagher R, Selzer ML, Lapides J. Carcinoma of the penis and the anti circumcision crusade. J Urol 1973;110:79-80.

Accepted for publication 17 December 1990 